\title{
Uitleg in commerciële verhoudingen naar Nederlands en Engels recht: de betekenis van 'business common sense' als gezichtspunt
}

\author{
Mr.drs. M. van Kogelenberg*
}

\section{Inleiding}

Op 24 februari 2017 deed de Hoge Raad uitspraak in de zaak Parkking Ontwikkeling B.V. c.s./Alberts q.q. ${ }^{1}$ Het ging in deze zaak om de vraag hoe correspondentie op grond van een gesloten overeenkomst - geen contractsbepalingen dus! - tussen twee professionele partijen dient te worden uitgelegd. Ook is onlangs een uitspraak gedaan door het Supreme Court van het Verenigd Koninkrijk inzake een uitlegkwestie die speelde in een commerciële verhouding. In die zaak, Wood v Capita Insurance Services, ${ }^{2}$ betrof het de uitleg van een vrijwaringsbeding. Hier ging het dus wél om de uitleg van een contractueel beding.

Over uitleg is al (heel) veel geschreven en gepubliceerd, recentelijk nog omvangrijk en in detail in het vorig jaar verschenen preadvies van Schelhaas en Valk voor de Vereniging voor Burgerlijk Recht. ${ }^{3}$ Ook anderszins is over uitleg van commerciële contracten regelmatig gepubliceerd, niet in de laatste plaats in

\footnotetext{
Mr. drs. M. van Kogelenberg is werkzaam als universitair docent privaatrecht bij het Molengraaff Instituut voor Privaatrecht van de Universiteit Utrecht.

1. HR 24 februari 2017, ECLI:NL:HR:2017:315 (Parkking Ontwikkeling B.V.c.s./Alberts q.q.).

2. Wood v Capita Insurance Services [2017] UKSC 24. Zie ook blog.ucall.nl/ voor een blog van de auteur over deze uitspraak.

3. H.N. Schelhaas \& W.L. Valk, Uitleg van rechtshandelingen (Preadvies voor de Vereniging voor Burgerlijk Recht), Zutphen: Paris 2016, meer in het bijzonder relevant voor deze bijdrage p. 43-49 (over uitleg in commerciële verhoudingen), p. 97-112 (over uitleg in Engels recht) en p. 135-137 (over de wenselijkheid van objectieve uitleg van commerciële contracten tussen grote professionele partijen).
}

MvV. ${ }^{4}$ Niettemin blijft dit leerstuk onverminderd relevant en bovendien blijkt steeds weer dat de materie 'glibberig' is. De uitgangspunten mogen in beginsel duidelijk zijn, toepassing in het concrete geval is allerminst een gelopen koers, zo blijkt ook uit de twee uitspraken die in deze bijdrage centraal staan. De meer concrete vraag in deze bijdrage is of de rechter in het Nederlandse c.q. Engelse recht in uitlegkwesties rekening houdt met 'zakelijke logica', ofwel 'business common sense'. Met andere woorden: kent de rechter gewicht toe aan het argument dat het vanuit commercieel oogpunt onwaarschijnlijk is dat een van beide partijen een bepaalde uitleg heeft voorgestaan?

Deze bijdrage start met een weergave van de uitspraak van de Hoge Raad (par. 2), gevolgd door die van het Supreme Court (par. 3). Vervolgens worden beide uitspraken geanalyseerd in het licht van de eerdergenoemde kwestie (par. 4). Ten slotte wordt deze bijdrage afgesloten met een conclusie (par. 5).

\section{De Parkking-zaak}

\subsection{Feiten en beslissingen rechtbank en hof}

De feiten in de onderhavige zaak zijn relatief eenvoudig. Het draait om de koop d.d. 1 september 2010 van een (appartementsrecht houdende) parkeergarage, waarbij Bolwerk als verkoper en (uiteindelijk) Parkking als koper is betrokken. Als derde partij is ook Lirema betrokken. Deze partij staat garant voor de koper. In de koopovereenkomst is een bepaling opge-

4. Zie o.m. R.P.J.L. Tjittes, Uitleg van schriftelijke contracten, RMThemis 2005, afl. 1, p. 2-29; R.P.J.L. Tjittes, Terug naar de tekst. Een herwaardering van de tekstuele uitleg van contracten, WPNR 2007/6709, p. 417-423; M.S. Breeman, Vijf jaar 'taalkundige uitleg' van commerciële contracten; een overzicht, MvV 2012, afl. 11, p. 327-334; D. Beenders \& J.W. Meijer, Uitleg van commerciële contracten in de praktijk, AA 2013, p. 646-657; J.W.A. Dousi, De entire agreement clause naar Amerikaans en Nederlands recht: afbakening, geen uitleg, Contracteren 2013, afl. 4, p. 126-133; P.S. Bakker, Uitleg van een derdenbeding in een verzekeringspolis. Enkele beschouwingen naar aanleiding van HR 19 april 2013, NJ 2013/239, MvV 2015, afl. 3, p. 89-96; H.N. Schelhaas, Pacta sunt servanda bij commerciële contracten, NTBR 2008/21, p. 150-160. 


\section{Maandblad \\ Vermogensrecht}

nomen (art. 21) inzake de wijze van financiering door de koper van deze garage en een daarbij geformuleerd voorbehoud in de vorm van een ontbindende voorwaarde. De financiering moet drie maanden voor de oplevering, die gepland staat op 15 december 2011 - dus op 15 september 2011 -, rond zijn. Lukt het niet om financiering te verkrijgen, dan kan zowel koper als verkoper een beroep doen op de ontbindende voorwaarde. Volgens art. 21.3 van de overeenkomst verbeurt de koper een boete als deze geen beroep doet op de ontbindende voorwaarde en alsnog de garage niet afneemt op de datum van oplevering.

Op 14 september 2011 laat Parkking aan Bolwerk per brief weten dat het nog niet gelukt is om financiers te vinden, maar dat zij wel mogelijkheden ziet als er nog iets meer tijd wordt gegeven om de financiering rond te krijgen. In de brief vraagt zij een maand uitstel om de financiering nog rond te krijgen. Tegelijkertijd beroept Parkking zich op de ontbindende voorwaarde, mocht Bolwerk niet akkoord gaan met de verlenging van de financieringstermijn. Bolwerk gunt vervolgens Parkking de extra maand, daarbij benadrukkend dat de rest van de overeenkomst ongewijzigd van kracht blijft. De termijn is daarna nog tweemaal verlengd met instemming van Bolwerk tot 25 november 2011.

Parkking laat op en na 25 november niets van zich horen en daarop roept Bolwerk art. 21.3 van de overeenkomst in. Bolwerk stelt dat Parkking zich niet op de ontbindende voorwaarde heeft beroepen en ook geen financiering heeft gevonden. Daarom verbeurt zij direct een boete van $€ 520.000$.

Parkking verweert zich door te stellen dat in gesprekken tussen september en november met Bolwerk duidelijk is geworden dat zij bezig was een koper voor de parkeergarage te vinden en dat Parkking niet (meer) de intentie had zélf de parkeergarage te kopen, omdat al op 14 september duidelijk was dat geen bank een dergelijke investering wilde doen. Deze lezing wordt door Bolwerk ontkend. Op 17 januari 2012 eist Bolwerk nakoming van de verplichtingen uit de overeenkomst dan wel betaling van de contractuele boete. In april 2012 wordt Bolwerk failliet verklaard. De curator neemt de procedure over.

De Rechtbank Zeeland-West-Brabant wijst de vordering ter zake de betaling van de boete toe. ${ }^{5}$ Het Hof 's-Hertogenbosch bekrachtigt het oordeel van de rechtbank. In het arrest is met name overweging 3.6.2 van belang. Daarin oordeelt het gerechtshof als volgt:

'In het onderhavige geval is sprake van een overeenkomst tussen zakelijke partijen (Parkking c.s. en Bolwerk), die voor zover bekend ten tijde van de litigieuze correspondentie niet door juridisch deskundige raadslieden werden bijgestaan, met betrekking tot een zuiver commerciële

5. Rb. Zeeland-West-Brabant 20 maart 2013 en 26 juni 2013, zaak C/02/248201/HA ZA 12-265, n.g. (Alberts q.q./Parkking). transactie over een onroerende zaak. Als uitgangspunt heeft daarom te gelden dat beslissend gewicht [dient] te worden toegekend aan de meest voor de hand liggende taalkundige betekenis van de woorden van de brief van Parkking c.s. van 14 september 2011, gelezen in het licht van de overige, voor de uitleg relevante bepalingen van de overeenkomst.' 6

Uit de brief en de overeenkomst kan volgens het gerechtshof niet worden afgeleid dat Parkking een beroep heeft gedaan op de ontbindende voorwaarde. Weliswaar heeft Parkking naar een andere koper of belegger gezocht, maar daarmee heeft Parkking de overeenkomst niet opzijgezet of gerelativeerd.

\subsection{Oordeel Hoge Raad}

Parkking gaat tegen voornoemd oordeel van het hof in cassatie. $\mathrm{Zij}$ klaagt tegen het oordeel dat zij zich niet heeft beroepen op de ontbindende voorwaarde en stelt met name het oordeel van het hof dat bij de uitleg van de brief van Parkking c.s. aan Bolwerk van 14 september 2011 beslissend gewicht dient te worden toegekend aan de meest voor de hand liggende taalkundige betekenis van de woorden van de brief, aan de orde. ${ }^{7}$

De Hoge Raad beantwoordt de vraag aan de hand van welke maatstaf de desbetreffende brief moet worden uitgelegd, als volgt in r.o. 3.3.2:

'De vraag hoe deze brief moet worden uitgelegd, dient te worden beantwoord aan de hand van de wilsvertrouwensleer, zoals neergelegd in de art. 3:33 en 3:35 BW. Daarbij zijn alle omstandigheden van het geval van belang en komt geen beslissend gewicht toe aan de meest voor de hand liggende taalkundige betekenis van de in de brief gebruikte bewoordingen, ook niet als uitgangspunt. Het onderdeel klaagt derhalve terecht dat het hof is uitgegaan van een onjuiste rechtsopvatting.'

Bovendien klaagt Parkking dat het hof eraan is voorbijgegaan dat zij wel degelijk gemotiveerd heeft onderbouwd dat zij zelf niet kon kopen wegens het ontbreken van een financieringsmogelijkheid en daarom op zoek was gegaan naar een belegger en - dat is het belangrijkst - dat zij hierover ook met Bolwerk heeft gesproken. De Hoge Raad honoreert ook deze klacht onder verwijzing naar de memorie van grieven en oordeelt dat het arrest van het hof op dit punt onvoldoende is gemotiveerd.

\section{De Wood-zaak}

\subsection{Feiten en beslissingen High Court en Court of Appeal}

Op 29 maart 2017 deed het Engelse Supreme Court uitspraak in de zaak Wood v Capita Insurance Services. Het draaide in

6. Hof 's-Hertogenbosch 8 september 2015, ECLI:NL:GHSHE: 2015:3456.

7. HR 24 februari 2017, ECLI:NL:HR:2017:315 (Parkking Ontwikkeling B.V.c.s./Alberts q.q.), r.o. 3.3.1. 
deze zaak om de uitleg van een vrijwaringsbeding opgenomen in een overnamecontract tussen verkoper Wood en koper Capita. Tijdens het overnameproces is een SPA (share purchase agreement) tussen partijen opgesteld. Daarin is onder meer een vrijwaringsbeding opgenomen dat Capita beschermt tegen mogelijke problemen die voortkomen uit de periode voor de overname. Het beding is als volgt geformuleerd:

'The Sellers undertake to pay to the Buyer an amount equal to the amount which would be required to indemnify the Buyer and each member of the Buyer's Group against all actions, proceedings, losses, claims, damages, costs, charges, expenses and liabilities suffered or incurred, and all fines, compensation or remedial action or payments imposed on or required to be made by the Company following and arising out of claims or complaints registered with the FSA, the Financial Services Ombudsman or any other Authority against the Company, the Sellers or any Relevant Person and which relate to the period prior to the Completion Date pertaining to any mis-selling or suspected mis-selling of any insurance or insurance related product or service. ${ }^{8}$

Het lijkt eenvoudig. Als blijkt dat Wood met zijn bedrijf op onheuse wijze verzekeringen heeft verkocht en derden daardoor schade hebben geleden in de periode dat Capita nog geen eigenaar van het bedrijf was, dan moet Wood de gedupeerden betalen en niet Capita. Uit de clausule lijkt echter voort te vloeien dat het initiatief van de claim moet uitgaan van de benadeelde partij: deze moet een claim hebben ingediend bij het bedrijf of bij een toezichthoudende instantie (de FSA). Als daaruit schade voortvloeit voor het bedrijf en dus voor Capita, kan die schade worden verhaald.

Precies daar zit het probleem. Er zijn verkeerde (te dure) verzekeringen verkocht door het door Capita overgenomen bedrijf en dat heeft geleid tot schade bij gedupeerden. Maar het zijn niet de gedupeerden zelf die actie hebben ondernomen. De toezichthoudende instantie heeft zélf onderzoek gedaan en daaruit is naar voren gekomen dat Woods bedrijf in een bepaalde periode op dubieuze wijze veel te dure verzekeringen heeft verkocht zonder dat duidelijk is hoe de kosten voor die verzekering precies waren opgebouwd. Er is een vergoedingsregime ontworpen door de FSA, dat is voorgelegd aan het bedrijf, dat inmiddels in handen was van Capita. Capita heeft dat regime geaccordeerd en heeft zich vervolgens omgedraaid naar Woods. Het gaat om een aansprakelijkheid ter hoogte van $£ 2,5$ miljoen.

Wood betoogt dat in dit geval de onderhavige claim niet gedekt is, omdat het initiatief tot het betalen van schadevergoeding niet kwam van de gedupeerden, maar van de FSA. De formulering van de vrijwaring biedt in een dergelijk geval niet de ruimte voor een beroep op de vrijwaring, aldus Woods.

8. Wood v Capita Insurance Services [2017] UKSC 24, r.o. 18.
De rechter in eerste aanleg - het High Court - verwerpt Woods betoog en onderschrijft de benadering van Capita. ${ }^{9}$ Volgens de rechter was de clausule zo ruim mogelijk geformuleerd om alle mogelijke gevallen van het optreden van schade ten gevolge van onrechtmatige acties in de periode voor de overname te dekken. De met name genoemde acties in de clausule zouden bovendien meer een illustratie vormen van de wijze van intreden van schade dan een limitatieve opsomming beogen. Bovendien ontleedt en interpreteert de rechter de clausule zodanig dat men hem zo dient te lezen dat 'verliezen' onder het beding vallen, zonder dat een directe klacht of een actie van de rechtstreeks gedupeerde nodig is.

Het Court of Appeal kiest een heel andere koers. ${ }^{10} \mathrm{Bij}$ monde van Lord Justice (LJ) Clark wordt een principiëlere route gekozen, die zijn vertrekpunt vindt bij de bewoordingen van de clausule. LJ Clark overweegt dat alleen een onwaarschijnlijke taalkundige interpretatie van de clausule meebrengt dat ook verliezen zijn gedekt die niet door middel van een 'claim' van de benadeelde aan de orde zijn gekomen. Interessant wordt het wanneer LJ Clark de overweging van het High Court bespreekt, waarin naar voren komt dat er geen enkele goede commerciële reden zou zijn voor partijen om de clausule zo te formuleren dat een reëel verlies dat via een initiatief van de FSA wordt gerealiseerd en niet via de benadeelde zelf, niet gedekt zou zijn. LJ Clark makkt met die voor Capita voordelige interpretatie korte metten, omdat hij redeneert dat hoewel een dergelijke clausule niet voordelig is voor Capita, Wood goede redenen gehad kan hebben om de clausule zo te schrijven. Hij geeft als voorbeeld de overweging dat een benadeelde partij binnen afzienbare tijd wel zou ageren, terwijl een onderzoek van een toezichthoudende instantie ook nog veel later na de koop kan plaatsvinden en daardoor te onvoorspelbaar is. Met andere woorden: LJ Clark is heel terughoudend om deze clausule uit te leggen aan de hand van het gezichtspunt 'business common sense'.

\subsection{Oordeel Supreme Court}

Ook bij het Supreme Court kreeg Capita geen gelijk. De precieze betekenis van het bewuste vrijwaringsbeding kon volgens Lord Hodge prima worden geconstrueerd door niet alleen naar de taalkundige betekenis van het beding te kijken, maar ook de contractuele context goed in ogenschouw te nemen. In het contract waren allerlei andere garanties en vrijwaringen opgenomen die een restrictieve uitleg van het onderhavige beding konden rechtvaardigen. Aan een aantal andere garanties en vrijwaringen was bijvoorbeeld een tijdslimiet verbonden - uiteraard een gebruikelijke gang van zaken. Dat aan de litigieuze clausule juist géén tijdslimiet was verbonden, maakte het waarschijnlijker dat de clausule op andere wijze restrictief bedoeld was. Het resultaat van deze restrictieve uitleg was dat Capita het betaalde bedrag aan schadevergoeding niet meer op

9. Wood v Sureterm Direct Ltd \& Capita Insurance Services Ltd [2014] EWHC 3240 (Comm).

10. Wood v Sureterm Direct Ltd \& Capita Insurance Services Ltd [2015] EWCA Civ 839. 


\section{Maandblad \\ Vermogensrecht}

Wood kon verhalen. Lord Hodge besluit zijn Opinion, die door de andere vier 'Lords' gevolgd wordt, met de volgende overweging:

'From Capita's standpoint the SPA may have become a poor bargain (...). But it is not the function of the court to improve their bargain.' ${ }^{\prime 1}$

Het kan best zijn dat Capita een slechte deal heeft gesloten, maar het behoort niet tot de taak van de rechter om van een slechte deal een betere deal te maken. Zo makt het Supreme Court duidelijk aan partijen én hun advocaten dat zij vooraf goed moeten onderhandelen en niet naderhand de rechter kunnen vragen te hulp te schieten als het onderhandelingsresultaat in de vorm van het uiteindelijk gesloten contract ongunstig blijkt te zijn.

\section{Analyse}

Benadrukt zij dat het in de Parkking-zaak niet gaat om uitleg van een clausule in het contract, maar om de bewoordingen van een brief die betrekking heeft op het contract. Welbeschouwd gaat het dus niet om de uitleg van een contract(sbepaling) - een meerzijdige rechtshandeling -, maar om de uitleg van een eenzijdig opgesteld document. Dit document kan worden gekwalificeerd als een eenzijdig gerichte rechtshandeling ${ }^{12}$ en dan lijkt dit onderscheid niet van groot belang voor de vraag welke uitlegmethode dient te worden gevolgd. Ook in het geval van een eenzijdig gerichte rechtshandeling gaat het om de toepassing van de wilsvertrouwensleer, zoals ook nader en expliciet geadresseerd door Valk en meer in detail door Spierings. ${ }^{13}$ De welbekende Haviltex-formule, die in beginsel is geschreven voor de uitleg van een bepaling in een schriftelijk contract, is niets anders dan een herformulering van deze wils-

11. Wood v Capita Insurance Services [2017] UKSC 24, r.o. 41.

12. De brief bevat ten eerste informatie over mogelijke financiers. Het verstrekken van deze informatie heeft als doel de gemaakte afspraken hieromtrent na te komen en de koop van de parkeergarage vooralsnog niet te doen stranden. Ten tweede bevat de brief een voorwaardelijk beroep op een ontbindende voorwaarde, dat is in ieder geval een beoogd rechtsgevolg.

13. Asser/Hartkamp \& Sieburgh 6-III 2014/104; Schelhaas \& Valk 2016, p. 18; C. Spierings, De eenzijdige rechtshandeling (diss. Nijmegen), Deventer: Wolters Kluwer 2016, nr. 430. vertrouwensleer. ${ }^{14}$ De Hoge Raad is in zijn oordeel zuiver in de leer en verwijst juist om deze reden - het gaat immers niet om een contractuele bepaling - niet rechtstreeks naar het Haviltex-arrest, maar uitsluitend naar art. 3:33 en 3:35 van het Burgerlijk Wetboek (BW). Dat de taalkundige uitleg van de brief niet beslissend is, ook niet als uitgangspunt, is dan geen nieuws. ${ }^{15}$

Aan deze uitspraak is goed te zien dat de wilsvertrouwensleer ook in deze gedaante volstrekt tot zijn recht komt. Het gaat immers om de zin die Parkking en Bolwerk redelijkerwijs aan de brief van 14 september 2011 hebben mogen toekennen en op hetgeen zij in de gegeven omstandigheden redelijkerwijze van elkaar hebben mogen verwachten. Bolwerk was er door gesprekken met Parkking al van op de hoogte dat Parkking de garage niet kón en wilde kopen vanwege de onmogelijkheid om gewone financiering te krijgen. Alleen een optie met beleggers die zelf kochten, stond nog open.

De advocaat-generaal ${ }^{16}$ - waarschijnlijk niet geheel toevallig ook een van de auteurs van het preadvies - ontleedt helder dat de stelling dat zuiver taalkundige uitleg als uitgangspunt is aangewezen, omdat het om een commerciële transactie gaat, al niet correct is. Het arrest Meyer/Pontmeyer, ${ }^{17}$ waaraan het hof blijkbaar probeert vast te knopen, komt het dichtst in de

14. In Asser/Hartkamp \& Sieburgh 6-III 2014/129 wordt de wilsvertrouwensleer als volgt omschreven: 'Zoals gezegd, wordt de vraag of een overeenkomst tot stand is gekomen en zo ja met welke inhoud, beantwoord aan de hand van een op de relevante beginselen berustende normatieve waardering van feiten en omstandigheden, waaronder in het bijzonder zijn begrepen de in verklaringen en gedragingen uitgedrukte wil van de partijen en het gerechtvaardigd vertrouwen.' Die formulering sluit aan bij de door de Hoge Raad geformuleerde regel in het arrest Haviltex (HR 13 maart 1981, NJ 1981/635): 'De vraag hoe in een schriftelijk contract de verhouding van pp. is geregeld en of dit contract een leemte laat die moet worden aangevuld, kan niet worden beantwoord op grond van alleen maar een zuiver taalkundige uitleg van de bepalingen van dat contract. Voor de beantwoording van die vraag komt het immers aan op de zin die pp. in de gegeven omstandigheden over en weer redelijkerwijs aan deze bepalingen mochten toekennen en op hetgeen zij te dien aanzien redelijkerwijs van elkaar mochten verwachten. Daarbij kan mede van belang zijn tot welke maatschappelijke kringen pp. behoren en welke rechtskennis van zodanige pp. kan worden verwacht.'

15. Zie ook D.E. Burgers, Over het (uitleg)verschil tussen een zakelijke brief en een commerciële overeenkomst, Bb 2017/33, p. 117-119.

16. Concl. A-G Valk, ECLI:NL:PHR:2016:1334, r.o. 2.4 en 2.5.

17. HR 19 januari 2007, ECLI:NL:HR:2007:AZ3178, NJ 2007/575 (Meyer/Pontmeyer). In dit arrest accordeert de Hoge Raad een op de casus toegesneden invulling van de Haviltex-formule door het hof, waarbij veel nadruk ligt op de taalkundige interpretatie van de contractuele clausule. Zie r.o. 3.4.3: 'Het hof heeft met zijn hiervoor in 3.4.1 samengevatte overwegingen tot uitdrukking gebracht dat voor het antwoord op de vraag welke zin partijen in de gegeven omstandigheden over en weer redelijkerwijze mochten toekennen aan de omstreden woorden in art. 8 onder b, SPA en wat zij te dien aanzien redelijkerwijze van elkaar mochten verwachten, in de door het hof in rov. 8.1 genoemde omstandigheden, waaronder de aard van de transactie, de omvang en gedetailleerdheid van het contract, de wijze van totstandkoming ervan en in het bijzonder de hierboven onder 3.3.3 (d) geciteerde "entire agreement clause" van art. 17.5 SPA, als uitgangspunt beslissend gewicht dient te worden toegekend aan de meest voor de hand liggende taalkundige betekenis van die woorden, gelezen in het licht van de overige, voor de uitleg relevante bepalingen van de SPA.' 
buurt van deze benadering, maar het oordeel in die kwestie is door de Hoge Raad in ieder geval sinds het arrest Lundiform/ Mexx ${ }^{18}$ minst genomen genuanceerd. Bovendien was in dat arrest - dat overigens over uitleg van een contract ging - ook nog sprake van een zogenaamde entire agreement clause, een clausule die met zich kan brengen dat de rechter eerder op het pad komt van een objectievere uitlegmethode. ${ }^{19}$ Daar komt dan nog bij dat in de Parkking-zaak partijen zonder deskundige juridische hulp het contract hebben opgesteld. Dat maakt de relevantie van een zuiver taalkundige uitleg des te kwestieuzer.

Binnen commerciële verhoudingen ligt het als het gaat om contractsuitleg, aldus de Hoge Raad, met inachtneming van de Haviltex-formule in veel gevallen voor de hand om meer gewicht toe te kennen aan de tekst van de betrokken bepaling, omdat partijen vaak langdurig en met behulp van deskundige bijstand het contract hebben opgesteld. ${ }^{20}$ Mijns inziens betekent dat niet meer dan dat de kans groter is dat de bedoelingen van partijen ook daadwerkelijk gestold zijn in het contract, althans geacht worden te zijn, omdat over dit contract bewust is onderhandeld. Het dient nog maar eens herhaald, dat de Hoge Raad ook al in het Haviltex-arrest het belang van de bewoordingen van het contract aangeeft en bij de relevante omstandigheden die meewegen bij de uitleg van de bepaling als enige concrete omstandigheden noemt de hoedanigheid van betrokken partijen en welke rechtskennis van hen mag worden verwacht. Dat betekent dus ook dat wanneer partijen géén rechtskundige bijstand hebben gehad, het niet bepaald voor de hand ligt om meer gewicht toe te kennen aan de bewoordingen van de uit te leggen bepaling of brief, maar in plaats daarvan juist de (geobjectiveerde) bedoelingen van partijen (weer) centraal te stellen.

In het Engelse recht geldt in beginsel een objectievere benadering dan in het Nederlandse recht. De algemene maatstaf voor uitleg is ontwikkeld sinds het arrest Prenn v Simmonds, ${ }^{21}$ en in moderne tijden geherformuleerd in het arrest Investors Compensation Scheme v West Bromwich Building Society ${ }^{22}$ en meer recent in Rainy Sky v Kookmin Bank. ${ }^{23}$ Naar aanleiding van deze uitspraken formuleert Lord Hodge dit uitgangspunt als volgt in de Wood-zaak:

'The court's task is to ascertain the objective meaning of the language which the parties have chosen to express their agreement. It has long been accepted that this is not a literalist exercise focused solely on a parsing of the wording of

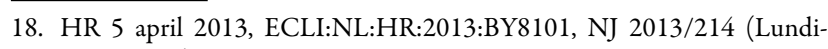
form/Mexx).

19. Zie wel kritisch over deze gang van zaken Dousi, in: Dousi 2013, waarin hij betoogt dat een entire agreement clause in beginsel slechts beoogt het object van uitleg te reguleren en geen uitlegmethode voorschrijft.

20. Zie ook Schelhaas \& Valk 2016, p. 135-137.

21. Prenn v Simmonds [1971] 1 WLR 138.

22. Investors Compensation Scheme v West Bromwich Building Society [1998] 1 WLR 896.

23. Rainy Sky v Kookmin Bank [2011] 1 WLR 2900. the particular clause but that the court must consider the contract as a whole and, depending on the nature, formality and quality of drafting of the contract, give more or less weight to elements of the wider context in reaching its view as to that objective meaning. ${ }^{24}$

Uitgangspunt is dus niet het subjectieve perspectief (wat waren de bedoelingen van partijen?), maar het objectieve perspectief (wat hebben partijen verklaard en hoe moet dat worden begrepen binnen de context van het contract als geheel?).

Dat perspectief kan verstrekkende consequenties hebben voor onoplettende partijen. Partijen moeten bijzonder waakzaam zijn bij het aangaan van een contract, zoals blijkt uit het recente arrest Arnold v Britton. ${ }^{25}$ In deze kwestie ging het om een leaseovereenkomst ten aanzien van vakantiehuisjes op een vakantiepark. De overeenkomst was gesloten in de jaren zeventig van de vorige eeuw. In deze overeenkomst was een clausule opgenomen waaruit voortvloeide dat de lessee verplicht was servicekosten te betalen. Omdat het om behoorlijk wat huisjes ging, waren er ook nogal wat verschillende overeenkomsten met allemaal een vergelijkbare clausule op dit punt. In enkele van deze overeenkomsten was de clausule zo geformuleerd dat het door de lessee te betalen startbedrag van $£ 90$ pond elk jaar met $10 \%$ zou worden verhoogd. Het ging daarbij om een lease van 99 jaar. Dat zou betekenen dat de lessee in 2072 de onwaarschijnlijk hoge bijdrage zou moeten betalen van meer dan $£ 550.000$. Vanzelfsprekend dus dat de lessee in dit geval betoogt dat dat nooit de bedoeling kon zijn geweest van de clausule en dat 'business common sense' met zich brengt dat deze clausule zo moet worden begrepen dat het te betalen bedrag nooit de werkelijk gemaakte servicekosten mag overstijgen.

Het is dit begrip 'business common sense' dat in de zaak Arnold v Britton, maar ook in de zaak Wood v Capita Insurance Services, door een van partijen wordt gebruikt om te proberen meer ruimte voor de rechter te creëren om buiten de tekstuele interpretatie van een bepaling een andere betekenis aan de betreffende bepaling toe te kennen. Dit begrip komt niet uit de lucht vallen, maar werd al eerder gebruikt in de zaak Rainy Sky v Kookmin Bank. Uit deze zaak komt naar voren dat wanneer de rechter er via de 'conventionele' uitlegroute niet uitkomt, dit begrip mogelijk de rechter kan helpen om de knoop door te hakken:

'(...) it is in essence that, where a term of a contract is open to more than one interpretation, it is generally appropriate to adopt the interpretation which is most consistent with business common sense. ${ }^{26}$

Met andere woorden: eerst moet worden verkend of tekstuele uitleg binnen de context van het contract tot een plausibele

24. Wood v Capita Insurance Services [2017] UKSC 24, r.o. 10

25. Arnold v Britton [2015] UKSC 36, 2 WLR 193.

26. Rainy Sky v Kookmin Bank [2011] 1 WLR 2900, r.o. 30. 
uitleg leidt. De rechter gaat dus partijen beslist niet helpen om een voordeliger deal te construeren met het argument dat 'business common sense' met zich brengt dat een bepaalde clausule nooit geaccepteerd zou worden. En langs deze lijn wordt ook besloten in Arnold v Britton.

Lord Neuberger verwoordt in die zaak de meerderheidsopinie van het Supreme Court (vier tegen een) en die valt niet uit in het voordeel van de lessee. Het is niet aan de rechter om achteraf een 'fair' contract te construeren, wat dat ook mag betekenen. Dat dat in dit geval uiterst ongelukkig uitpakt, is een feit - dat erkent hij ook -, maar het Engelse contractenrecht geeft de rechter geen ruimte om in dit geval de lessee tegemoet te komen. Een sterk argument van Lord Neuberger is dat de interpretatie van de lessee betekent dat deze clausule nooit commercieel nadelig voor hem kan uitvallen: in het slechtste geval betaalt de lessee de werkelijk gemaakte kosten en in elk ander geval moet de lessor bijpassen. Dat laatste lijkt heden ten dage - met al jarenlang een tamelijk lage inflatie van maximaal $4 \%$ - onwaarschijnlijk, maar tegen de achtergrond van het moment waarop het contract is gesloten, is dat niet zo vreemd gedacht, want in de jaren zeventig en (begin) jaren tachtig lag het inflatieniveau regelmatig op $10 \%$ of zelfs erboven. ${ }^{27}$

Alleen Lord Carnwath laat zich door de lessee overtuigen, maar hij heeft daarvoor de tournure nodig dat het commercieel ondenkbaar is dat partijen dit zouden kunnen hebben bedoeld. Daarmee plaatst de rechter zich naar de mening van de meerderheid van het Supreme Court te veel op de stoel van de contractspartijen - hoe sympathiek en begrijpelijk de uitkomst ook is. Lord Neuberger ziet geen andere mogelijkheid voor de lessee dan aan de wetgever te vragen om een specifieke regeling te ontwerpen voor een situatie als de voorliggende, namelijk waarin extreem nadelige gevolgen voor de lessees kunnen worden verzacht.

\section{Conclusie}

Het Engelse recht plaatst in het algemeen, maar zeker ook in commerciële verhoudingen, een contextuele benadering voorop als het om uitleg gaat, waarbij de bewoordingen van het contract uiteraard ook een grote rol kunnen spelen. Een bepaling dient te worden uitgelegd met de tekst in de hand en met behulp van voor derden kenbare andere bronnen, met name het contract zelf en aanpalende documenten. Uitsluitend als deze benadering niet tot een eenduidige conclusie leidt, kunnen ook andere elementen bij de uitlegkwestie betrokken worden, zoals het gezichtspunt wat vanuit commercieel oogpunt een logische uitleg zou kunnen zijn. Dit gezichtspunt van de 'business common sense' kan - zo volgt uit de Wood-zaak - in genen dele een opzichzelfstaande rechtvaardiging zijn voor een bepaald type uitleg dat nadelige consequenties voor een van betrokken partijen wegneemt. De rechter gaat niet op de stoel van de contractant of zijn advocaat zitten: de rechter corri-

27. Zie bijv. de website inflation.eu met actuele en historische gegevens over het inflatieverloop per (EU-)land. geert geen slordige onderhandelingstechnieken of formuleringen om een contractueel evenwicht te bewerkstelligen, wat dat ook moge betekenen.

Het Nederlandse recht komt een commerciële partij iets meer tegemoet, zo blijkt uit de Parkking-zaak. ${ }^{28}$ Het ging in dit geval weliswaar niet om een contract, maar om een brief, maar het lijkt er niet op dat dit verschil mak. Niettemin geven de bewoordingen van de betrokken brief aanleiding te denken dat Parkking alleen een beroep op de ontbindende voorwaarde wilde doen, als Bolwerk geen uitstel wilde verlenen, en niet als het niet lukte om geen financiers te vinden. Zoals Burgers al terecht opmerkt, had Parkking zich een hele procedure kunnen besparen door op dit punt duidelijker te zijn geweest. ${ }^{29}$ Niettemin biedt het Nederlandse recht in dit geval voldoende aanknopingspunten om Parkking niet 'op te hangen' aan de formulering in de brief, maar ook de context erbij te betrekken. Die 'context' is wel een wat ruimere dan de Engelse, zo lijkt het, omdat bij die context ook daarmee samenhangende gebeurtenissen, zoals gesprekken, betrokken worden. Die context weegt bovendien ook zwaar mee, evenals - een stap verder - de kenbare bedoelingen van partijen. Het is dus niet zozeer 'business common sense' als zodanig die in dit geval als uitkomst heeft dat Parkking geen boete hoeft te betalen, maar het samenstel van verklaringen en gedragingen over en weer die maken dat Bolwerk er niet op mocht vertrouwen dat Parkking zich aan de overeenkomst zou committeren, in zoverre dat zij zo gemakkelijk een hoge boete zou willen betalen. De wilsvertrouwensleer heeft dus in dit geval als uitkomst dat een 'zakelijk logische' uitleg prevaleert - althans bezien vanuit het standpunt van Parkking -, maar die uitkomst betekent niet dat het gezichtspunt 'business common sense' als zodanig een zelfstandige betekenis heeft in het Nederlandse recht.

28. Zoals Schelhaas in het preadvies betoogt, zit er minder verschil in uitleg methode wanneer het om contracten tussen grote professionele partijen gaat die veel en deskundige juridische bijstand genieten, zie Schelhaas \& Valk 2016, p. 135-137.

29. Burgers 2017, p. 119. 